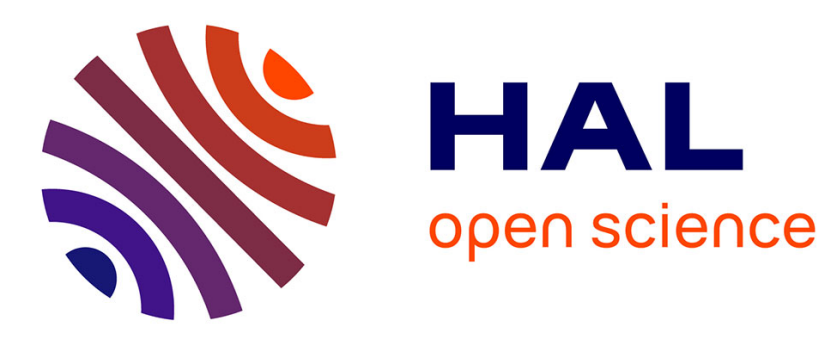

\title{
Toolpath dependent stability lobes for the milling of thin-walled parts
}

Sébastien Seguy, Francisco Javier Campa, Luis Norberto López de Lacalle, Lionel Arnaud, Gilles Dessein, Gorka Aramendi

\section{To cite this version:}

Sébastien Seguy, Francisco Javier Campa, Luis Norberto López de Lacalle, Lionel Arnaud, Gilles Dessein, et al.. Toolpath dependent stability lobes for the milling of thin-walled parts. International Journal of Machining and Machinability of Materials, 2008, 4 (4), pp.377-392. 10.1504/IJMMM.2008.023720 . hal-00963033

\section{HAL Id: hal-00963033 \\ https://hal.science/hal-00963033}

Submitted on 21 Mar 2014

HAL is a multi-disciplinary open access archive for the deposit and dissemination of scientific research documents, whether they are published or not. The documents may come from teaching and research institutions in France or abroad, or from public or private research centers.
L'archive ouverte pluridisciplinaire HAL, est destinée au dépôt et à la diffusion de documents scientifiques de niveau recherche, publiés ou non, émanant des établissements d'enseignement et de recherche français ou étrangers, des laboratoires publics ou privés. 


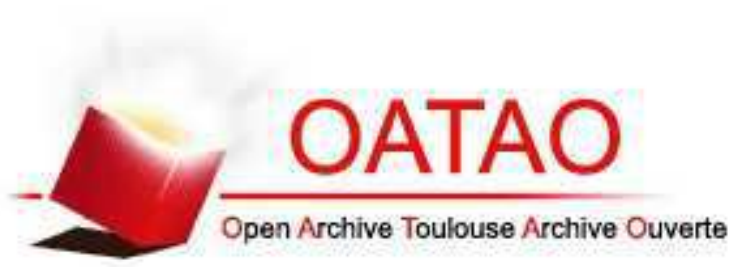

\section{Open Archive Toulouse Archive Ouverte (OATAO)}

OATAO is an open access repository that collects the work of Toulouse researchers and makes it freely available over the web where possible.

This is an author-deposited version published in: http://oatao.univ-toulouse.fr/ Eprints ID: 6508

To link to this article: DOI:10.1504/IJMMM.2008.023720

http://dx.doi.org/10.1504/IJMMM.2008.023720

\section{To cite this version:}

Seguy, Sebastien and Campa, Francisco J. and Lacalle, L. Norberto Lopez de and Arnaud, Lionel and Dessein, Gilles and Aramendi, Gorka Toolpath dependent stability lobes for the milling of thin-walled parts. (2008) International journal of machining and machinability of materials, vol. 4 ( $\left.n^{\circ} 4\right)$. pp. 377-392. ISSN 17485711

Any correspondence concerning this service should be sent to the repository administrator: staff-oatao@inp-toulouse.fr 


\title{
Toolpath dependent stability lobes for the milling of thin-walled parts
}

\author{
Sébastien Seguy \\ Ecole Nationale d'Ingénieurs de Tarbes, \\ Laboratoire Génie de Production, \\ 47 Avenue d'Azereix BP 1629, \\ Tarbes Cedex 65016, France \\ E-mail: sebastien.seguy@enit.fr

\section{Francisco J. Campa* and \\ L. Norberto López de Lacalle} \\ Department of Mechanical Engineering, \\ University of the Basque Country, \\ Alameda de Urquijo s/n, \\ Bilbao 48013, Spain \\ E-mail: fran.campa@ehu.es \\ E-mail: norberto.lzlacalle@ehu.es \\ ${ }^{*}$ Corresponding author
}

\section{Lionel Arnaud and Gilles Dessein}

Ecole Nationale d'Ingénieurs de Tarbes, Laboratoire Génie de Production,

47 Avenue d'Azereix BP 1629,

Tarbes Cedex 65016, France

E-mail: lionel.arnaud@enit.fr

E-mail: gilles.dessein@enit.fr

\section{Gorka Aramendi}

Fundación Fatronik,

Paseo Mikeletegi,

7, Parque Tecnológico,

San Sebastián 20009, Spain

E-mail: garamendi@fatronik.com

\begin{abstract}
The milling of thin-walled parts can become a seriously complex problem because the parts have variable dynamics. Firstly, the dynamics evolution of the part has been calculated through Finite Element Method (FEM) analysis. Then, the 3D stability lobes have been calculated for the thin walls and the thin floor. Finally, several milling tests have been performed in order to validate the predictions made by the model.
\end{abstract}


Keywords: chatter; milling; FEM; finite element method; thin workpiece.

Reference to this paper should be made as follows: Seguy, S., Campa, F.J., López de Lacalle, L.N., Arnaud, L., Dessein, G. and Aramendi, G. (2008) 'Toolpath dependent stability lobes for the milling of thin-walled parts', Int. J. Machining and Machinability of Materials, Vol. 4, No. 4, pp.377-392.

Biographical notes: Sébastien Seguy is presently preparing his $\mathrm{PhD}$ work at the Laboratory Genus of Production, France. His research focuses on the machining with variable spindle speed and dynamics behaviour in peripherical milling of thin-walled part.

Francisco J. Campa is currently working on his $\mathrm{PhD}$ in the Department of Mechanical Engineering at the University of the Basque Country. His research is focused in the machining of thin-walled parts and dynamics of the milling process.

L. Norberto López de Lacalle is a Professor in the Department of Mechanical Engineering at the University of the Basque Country. His research topics are high performance machining, machining of difficult-to-cut materials and new advances in manufacturing processes.

Lionel Arnaud is an Assistant Professor in the Department of Mechanical Engineering at the National Tarbes Engineering School. His current research interests include vibration analysis in manufacturing process, stability and dynamics in peripherical milling.

Gilles Dessein is an Assistant Professor in the Department of Production at the National Tarbes Engineering School. His research topics are HSM and CAD-CAM. His current research focus on stability and dynamics of milling process, solution against thin walled part vibrations and surface integrity.

Gorka Aramendi works as a Researcher in the Department of Manufacturing Processes at the Spanish Investigation Centre, Fatronik. His research topics are high speed machining, drilling of composite materials and ultrasonic assisted processes.

\section{Introduction}

These days, monolithic components are commonly used as structural parts in the aeronautical industry due to their homogeneity and excellent strength to weight ratio. Ribs, stringers, spars and bulkheads can be mentioned as an example. Monolithic parts are made of thin walls and webs, which confer enough stiffness to the whole part. Although they were usually made assembling several smaller parts, nowadays they are milled starting from a raw block of material and removing up to $95 \%$ of the weight of the initial block. Hence, a high productivity can only be achieved increasing the removal rate as much as possible. The drawback is that, at high removal rate conditions, the lack of stiffness of the thin walls and webs makes static and dynamic problems appear, particularly, the self-excited vibration called chatter, which is the most complex and difficult to avoid by manufacturers. As a consequence, unacceptable surface roughness levels, part damage and a lack of dimensional accuracy can be suffered.

However, the vibrations of the couple tool-part are known since the 1950s (Tobias and Fishwick, 1958). The first studies of the chatter machine-tool are related to 
continuous cutting processes, like the turning process, and modelled them with linear equations. Tlusty and Polacek (1963) succeeded in explaining the causes of these regenerative vibrations in the orthogonal case of the cut applied to turning. This knowledge is at the base of the stability lobes theory, which makes it possible to find the depth of cut according to the spindle speed, from which, the machining system will become unstable.

Studies on milling stability started later due to the complexity of modelling cutting forces, based on their variability in time and space. It is then about the middle of the 1990s, that the first modelling in analytical form appeared (Budak and Altintas, 1998a,b; Jensen and Shin, 1999). This theory is well applied in the case of the tools vibrations, because the dynamic characteristics are constant during all machining.

Methods dedicated to the highly interrupted cutting have only recently been developed. Davies and Balachandran (2000) developed a frequency domain model by making the assumption that the time of cut is very small compared to the tooth period; this modelling is well adapted when the cut is strongly discontinuous. Many authors (Bayly et al., 2003; Davies and Balachandran, 2000; Gradisek et al., 2005) demonstrated that this condition generated new stable zones inside unstable zones, due to period-doubling vibrations.

Chatter due to the excitation of the part has also been studied. In this case, this modelling cannot be applied directly because the characteristics of the part strongly vary during machining (Lapujoulade et al., 2002; Thevenot et al., 2006a). Budak (1994) studied not only the static deflexion of the thin wall but also developed a frequency domain simulation for varying dynamics of the wall and tool in axial direction. The stability lobes change during machining what leads to the addition of the third dimension, corresponding to the tool position (Thevenot et al., 2006b). New improvements were made by taking into account the vibrations related to the machine and with the tool (Bravo et al., 2005).

The case of thin floors has been less studied, maybe because it is a problem that traditionally has been solved with rigid fixtures. Smith and Dvorak (1998) proposed the selection of tool with zero corner radius for thin floor machining in order to minimise the excitation of the modes of the floor. However, a bull-nose end mill has to be used to leave a fillet radius between the floors and the walls, and the chatter appearance becomes possible. Several three dimensional stability models have been developed that can take into account the movement of the floor (Altintas, 2001; Campa et al., 2007).

Our objective is to apply on the same part the modelling usually implemented for the machining of thin walls and thin floors. This modelling is able to optimise the chatter free machining by means of an optimal spindle speed selection. The remainder of this paper is summarised as follows: Section 2 presents the part studied. The modelling based on Finite Element Method (FEM) calculus is shown in Section 3. Section 4 presents the stability model based on frequency analysis. Section 5 exposes the experimental work, the tests carried out, the surface roughness analysis and the correlation with the modelling. Section 6 concludes this work and presents the prospects.

\section{Studied part}

In order to have a part representative of the aeronautical milling problems, this study was focused on a part with the typical shape of a 'pocket' (see Figure 1). 
Figure 1 Aluminium 7075 T6 workpiece size (see online version for colours)

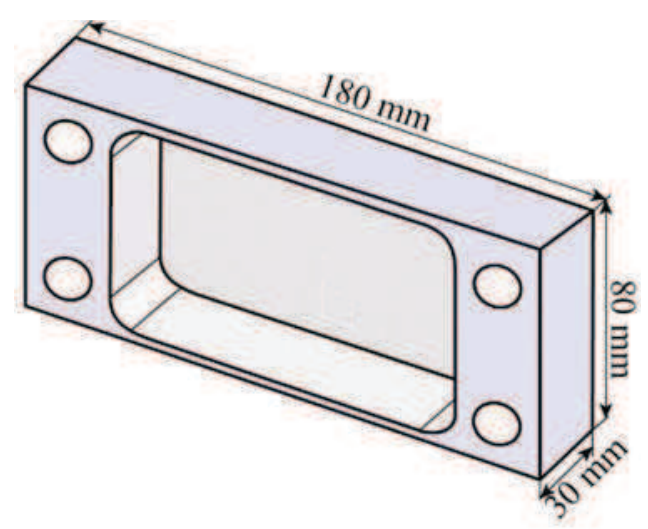

This part is made of two distinct types of thin walls: the floor and the lateral wall. The workpiece is made of an aluminium alloy 7075 T6 like structural parts. The dimensions are chosen in order to correlate with an industrial part. The thicknesses of the walls after machining are respectively of $1 \mathrm{~mm}$ for the floor and $3 \mathrm{~mm}$ for the walls.

The dynamic characteristics of this part are very complex, it cannot be represented by a simple mass spring. This part is characterised by several modes with specific modal shapes, so their corresponding natural frequencies, stiffnesses and damping ratios must be calculated.

For industrial partners, the evaluation of the manufacture of structures is based on standard criteria. In the case of structural parts for aeronautical purposes, the following criteria are typical:

Surface roughness: $3.2 \mu \mathrm{m}$.

Dimension tolerance: $\pm 0.15 \mathrm{~mm}$.

Geometrical flatness: $0.15 \mathrm{~mm}$ in the whole area and $0.05 \mathrm{~mm}$ in a straight direction.

\section{FEM calculation}

The pocket machining has been divided into two operations. Firstly, the pocketing of the floor has been carried out with a bull-nose end mill in order to have a fillet radius between the walls and the floor. The second is a finish milling of the walls with an end mill with zero corner radius.

Due to the variety of parameters involved, there are endless possibilities to do the pocketing, such as: the axial and radial depth of cut, down- or up-milling, strategy, initial thickness of the floor, etc. However, it is not the purpose of the authors to propose an optimal strategy, instead, the objective of this work is to improve the machining only by means of a stability lobes-based spindle speed selection. Thus, the milling strategy, the radial immersion $A_{\mathrm{e}}=10 \mathrm{~mm}$ and the milling mode: down-milling, were fixed. The initial thickness of the floor and consequently the axial depth of cut $A_{\mathrm{p}}$ are chosen through iteration calculating the modal parameters and the corresponding stability lobes. If the initial thickness is too small, the lobes indicate that milling becomes impossible. On the 
other hand, if it is too thick, the possibility of chatter appearance vanishes but cutting forces increase and the chip evacuation is difficult, therefore, a compromise was taken. In order to limit the calculus time, a parallel strategy as in Figure 3 has been selected for the floor, while the finishing of the wall was performed in contouring.

During the machining, the part dynamic characteristics evolve according to the tool position and the removal of material. The natural frequency decreases, during the machining. In order to predict this evolution, a traditional modelling by finite elements was used. Every step of the toolpath was discretised; for every $15 \mathrm{~mm}$, a modal analysis calculates the apparent stiffness and the natural frequency of the part. The model is parameterised in order to automate calculations. The part was modelled by 2D plates after a comparison with a 3D model, which concluded that the difference between them was lower than $0.3 \%$. What is more, the results provided by the $2 \mathrm{D}$ model were accurate enough and the computation time was reduced enormously.

Figure 2 shows the fourth modal shape of the part. Note that all the walls (side and floor) are coupled. The machining of the floor involves the excitation of the side walls.

Figure 2 Modal shape of the fourth mode (see online version for colours)

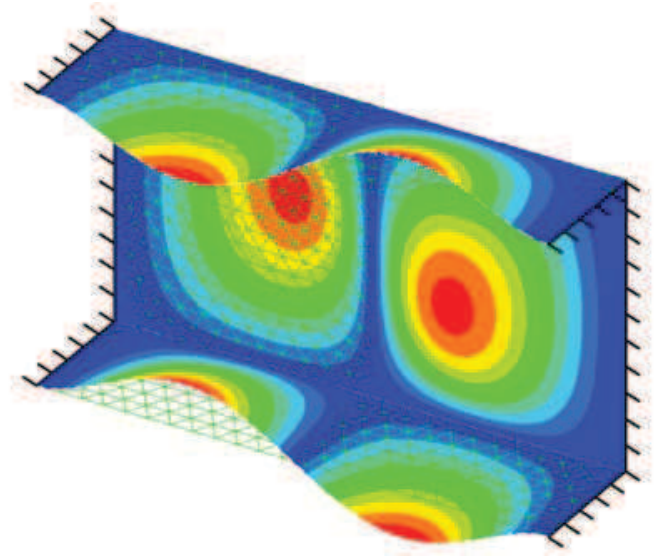

As the precision of the calculated frequencies has to be better than $1 \%$, hammer impact tests were conducted in order to adjust the finite element model to the real behaviour of the part. These tests were made before and after the machining. The damping ratio was obtained by hammer test because it is impossible to predict accurately.

Figure 3 shows the first four modes natural frequencies evolution in the case of floor machining. For the tests, the axial depth of cut was finally fixed at $A_{\mathrm{p}}=5 \mathrm{~mm}$ (6 to $1 \mathrm{~mm}$ thick). The strategy of milling modelled consisted of a ramp-down-milling (Step 1), return, followed by four alternating cuts in down-milling (Steps 2-5). During the machining of the floor, the natural frequencies change considerably. The first mode evolves from 3.25 to $1.7 \mathrm{kHz}$.

The thin wall was finished with a radial depth of cut of $0.1 \mathrm{~mm}$. In this case, as the material removal is very little, the natural frequency of the part is assumed constant, and only the apparent stiffness varies according to the tool position (Thevenot et al., 2006b). The stability lobes are computed along the toolpath in order to show the stiffness evolution. 
Figure 3 Natural frequency evolution for floor machining (see online version for colours)

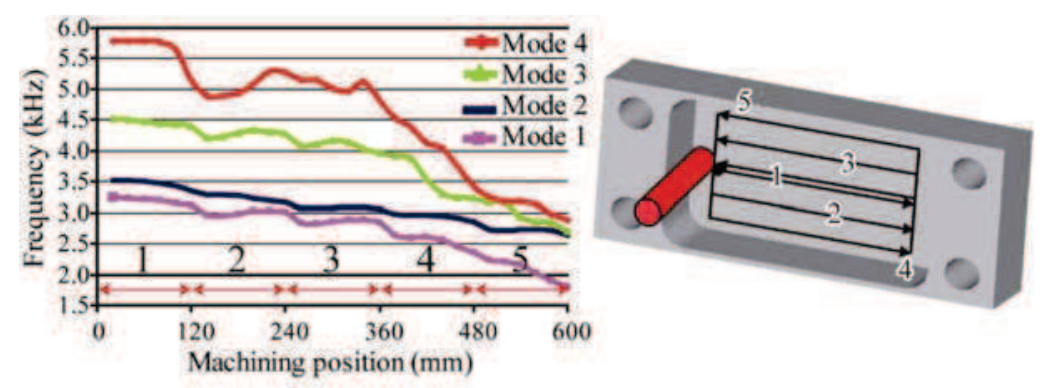

\section{Stability analysis model}

From the modal characteristics obtained by calculations and validated by tests, we can study the machining stability. For that, we quickly will present the models used for the floor and the side wall. The model here presented is based on the Budak and Altintas work (Altintas, 2001; Budak and Altintas, 1998a,b) and the averaging proposed by Campa et al. (2007).

\subsection{Floor}

\subsubsection{Dynamic chip thickness calculation}

The cutting edge $j$ cuts a dynamic chip thickness $h_{\mathrm{j}}$ that is calculated as a function of the difference of position between the actual edge and the previous edge that passed in that point, as in Campa et al. (2007):

$$
h_{j}=\left[\Delta x \sin \left(\phi_{j}\right)+\Delta y \cos \left(\phi_{j}\right)\right] \sin (\gamma)+\Delta z \cos (\gamma)
$$

\subsubsection{Calculation of the cutting forces}

The forces model relates the cutting forces with the dynamic displacements through (2). A linear forces model has been used in order to solve the stability problem. The characterisation of the specific cutting coefficients is based on a mechanistic model, and it has been done through several machining tests with a Kistler dynamometer. Hence, the cutting forces, tangential $f_{\mathrm{t}}$, radial $f_{\mathrm{r}}$ and axial $f_{\mathrm{a}}$, are:

$$
\left\{\begin{array}{l}
f_{\mathrm{t}} \\
f_{\mathrm{r}} \\
f_{\mathrm{a}}
\end{array}\right\}=K_{\mathrm{t}} A_{\mathrm{p}}\left\{\begin{array}{c}
1 \\
K_{\mathrm{r}}^{\prime} \\
K_{\mathrm{a}}^{\prime}
\end{array}\right\} h_{j}\left(\phi_{j}\right)
$$

where $K_{\mathrm{r}}^{\prime}$ and $K_{\mathrm{a}}^{\prime}$ are the specific radial and axial shearing coefficients 'normalised' to $K_{\mathrm{t}}$. Those forces are projected over the Cartesian axes as follows:

$$
\left\{\begin{array}{l}
f_{x} \\
f_{y} \\
f_{z}
\end{array}\right\}=\left[\begin{array}{ccc}
-\cos \phi_{j} & -\sin \gamma \sin \phi_{j} & \cos \gamma \sin \phi_{j} \\
\sin \phi_{j} & -\sin \gamma \cos \phi_{j} & \cos \gamma \cos \phi_{j} \\
0 & -\cos \gamma & -\sin \gamma
\end{array}\right]\left\{\begin{array}{l}
f_{\mathrm{t}} \\
f_{\mathrm{r}} \\
f_{\mathrm{a}}
\end{array}\right\}
$$


Substituting (2) in (3) and summing the forces for all the cutting edges $z$, forces and displacements get related by the matrix of directional coefficients $[\boldsymbol{A}(t)]$ in Equation (4).

$$
\{\boldsymbol{f}(t)\}=\frac{1}{2} A_{p} K_{t}[\boldsymbol{A}(t)]\{\Delta(t)\}
$$

\subsubsection{Calculation of the stability limit}

The incremental displacement for a given period of cut $T$ is:

$$
\{\Delta(t)\}=\left(1-e^{-i \omega_{\mathrm{c}} T}\right)\left[\boldsymbol{G}\left(i \omega_{\mathrm{c}}\right)\right]\{\boldsymbol{f}\} e^{i \omega_{\mathrm{c}} t}
$$

where $\left[\boldsymbol{G}\left(i \omega_{\mathrm{c}}\right)\right]$ includes the frequency response functions of both the tool and workpiece. Introducing (5) in (4), the following equation is obtained:

$$
\{\boldsymbol{f}(t)\}=\frac{1}{2} A_{\mathrm{p}} K_{\mathrm{t}}\left(1-e^{-i \omega_{\mathrm{c}} t}\right)[\boldsymbol{A}(t)]\left[\boldsymbol{G}\left(i \omega_{\mathrm{c}}\right)\right]\{\boldsymbol{f}(t)\}
$$

An analytical solution for (6) can be found, substituting the periodic matrix $[\boldsymbol{A}(t)]$ by its average term in the Fourier series expansion. Hence, (6) becomes an eigenvalue problem, where (7) defines the stability and the eigenvalue is (8):

$$
\begin{aligned}
& \operatorname{det}\left[[\boldsymbol{I}]+\Lambda\left[\mathbf{G}_{\mathrm{o}}\left(i \omega_{\mathrm{c}}\right)\right]\right]=0 \\
& \Lambda=-\frac{z}{2 \pi} A_{\mathrm{p}} K_{\mathrm{t}}\left(1-e^{-i \omega_{\mathrm{c}} T}\right)
\end{aligned}
$$

The critical depth of cut $A_{\mathrm{p} \text { lim }}$ and the corresponding spindle speeds $N$ for each lobe $m$ are obtained as:

$$
\begin{aligned}
& A_{\mathrm{plim}}=-\frac{2 \pi}{z K_{\mathrm{t}}} \operatorname{Re}(\Lambda)\left[1+\left(\frac{\operatorname{Im}(\Lambda)}{\operatorname{Re}(\Lambda)}\right)^{2}\right] \\
& N=\frac{60 \omega_{\mathrm{c}}}{z(\pi-2 \arctan ((\operatorname{Im}(\Lambda)) / \operatorname{Re}(\Lambda)))+2 \pi m}
\end{aligned}
$$

In highly interrupted cutting, the harmonic content of the cutting forces cannot be neglected, so several terms of Fourier series expansion of $[\boldsymbol{A}(t)]$ must be considered. Hence, Equation (7) becomes Equation (11), where $(r, m=0, \pm 1, \pm 2, \ldots)$ :

$$
\operatorname{det}\left[\delta_{r m}[I]-\frac{1}{2} A_{\mathrm{p}} K_{\mathrm{t}}\left(1-e^{-i \omega_{c} T}\right)\left[\boldsymbol{W}_{r-m}\left(i \omega_{\mathrm{c}}+i m \omega\right)\right]\right]=0
$$

This approach, known as multifrequency calculation, becomes more complex to solve, as requires iteration, but as a result, added lobes due to flip bifurcation chatter (Bayly et al., 2003; Davies and Balachandran, 2000; Gradisek et al., 2005) can be obtained, and the accuracy of the solution is improved. 


\subsubsection{Averaging}

For bull-nose end mills with a corner radius $r_{0}$, the angle $\kappa$ is variable along the tool axis direction, so it is necessary to find an average value to solve the stability problem (see Figure 4). The same has to be done with the cutting coefficients as they also vary. The method used here averages the cutting edge lead angle $\kappa$ at the middle of the cutting arc over the volume of the chip for a given depth of cut $A_{\mathrm{p}}$, so an average value can be obtained. When $A_{\mathrm{p}}$ is lower than the corner radius:

$$
\begin{aligned}
& \kappa_{1}=\arccos \left(\frac{r_{0}-z}{r_{0}}\right) \\
& r_{1}=\left(R-r_{0}\right)+r_{0} \sin \kappa_{1}
\end{aligned}
$$

Thus,

$$
\overline{\mathcal{K}}=\frac{\int_{0}^{A_{p}} \int_{\phi_{0}}^{\phi_{1}}\left(\kappa_{1} / 2 f_{z} \sin (\phi) r_{1} m\right) \mathrm{d} \phi \mathrm{d} z}{\int_{0}^{A_{p}} \int_{\phi_{0}}^{\phi_{1}}\left(f_{z} \sin (\phi) r_{1} m\right) \mathrm{d} \phi \mathrm{d} z}
$$

where

$$
m=\frac{\mathrm{d} \kappa}{\mathrm{d} z}=\frac{1}{\left(r_{0} \sqrt{\left(1-\left(\left(r_{0}-z\right)^{2}\right) / r_{0}^{2}\right)}\right)}
$$

Figure 4 Left: Tool geometry defining parameters. Right: Substitution of a non-linear geometry for a linear by means of an averaging procedure

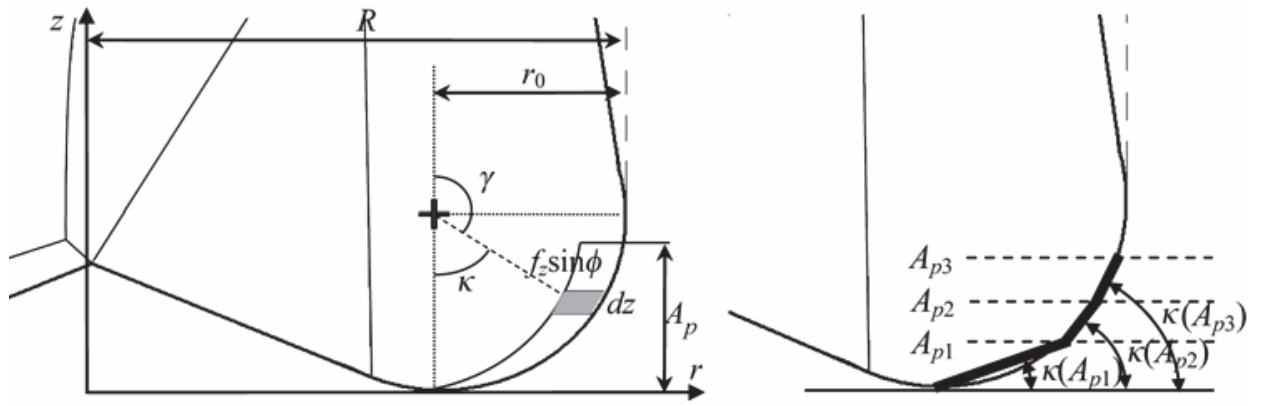

On the other hand, when the depth of cut is higher than the corner radius:

$$
\begin{aligned}
& \kappa_{2}=\frac{\left(r_{0} \times \pi / 2 \times \pi / 4+\left(z-r_{0}\right) \pi / 2\right)}{\left(r_{0} \times \pi / 2+\left(z-r_{0}\right)\right)} \\
& \bar{\kappa}=\frac{\int_{0}^{r_{0}} \int_{\phi_{0}}^{\phi_{1}}\left(\left(\kappa_{1} / 2\right) f_{z} \sin (\phi) r_{1} m\right) \mathrm{d} \phi \mathrm{d} z+\int_{r_{0}}^{A_{p}} \int_{\phi_{0}}^{\phi_{1}}\left(R\left(\kappa_{2} / 2\right) f_{z} \sin (\phi)\right) \mathrm{d} \phi \mathrm{d} z}{\int_{0}^{r_{0}} \int_{\phi_{0}}^{\phi_{1}}\left(f_{z} \sin (\phi) r_{1} m\right) \mathrm{d} \phi \mathrm{d} z+\int_{r_{0}}^{A_{p}} \int_{\phi_{0}}^{\phi_{1}}\left(R f_{z} \sin (\phi)\right) \mathrm{d} \phi \mathrm{d} z}
\end{aligned}
$$


Therefore, the average axial immersion angle is $\bar{\gamma}=180^{\circ}-\bar{\kappa}$ and the average height $\bar{z}=r_{0}-r_{0} \cos (\bar{\kappa})$.

With the modelling presented here, it is possible to plot the stability lobes for the floor, including the tool position during the whole machining (see Figure 7).

\subsection{Wall}

The tool is rigid compared to the workpiece, which is considered to be flexible. The workpiece moves only on the $y$ direction, locally like a single degree of freedom model (see Figure 5).

Figure 5 Wall modelling

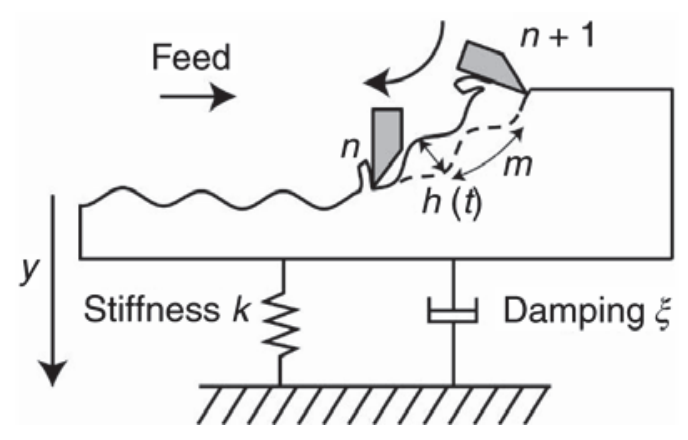

The complex transfer function of the part in the direction y is there:

$$
G_{y}\left(i \omega_{c}\right)=\frac{\omega_{0}^{2}}{k\left(\omega_{0}^{2}-\omega_{c}^{2}+2 \xi \omega_{0} \omega_{c} i\right)}
$$

A linear cutting law has been used, where: $F_{\mathrm{t}}=K_{\mathrm{r}} A_{\mathrm{p}} h(t)$ and $F_{\mathrm{r}}=k_{\mathrm{r}} F_{\mathrm{T}} \cdot K_{\mathrm{t}}$ is the tangential cutting force coefficients, $k_{\mathrm{r}}$ is the radial cutting force coefficient ratio and $h(t)$ is the chip thickness.

The equations of the model used to calculate the stability lobes for the wall are presented now (Budak and Altintas, 1998b). The axial depth of cut limit is expressed in the form:

$$
A_{\text {plim }}=\frac{1}{(z / 2 \pi) \alpha_{y y} K_{\mathrm{t}} \operatorname{Re}\left[G_{y}\left(i \omega_{\mathrm{c}}\right)\right]}
$$

where $z$ is the teeth number and $\alpha_{y y}$ the directional milling coefficient:

$$
\alpha_{y y}=\frac{1}{2}\left[-\cos (2 \theta)-2 k_{\mathrm{r}} \theta-k_{\mathrm{r}} \sin (2 \theta)\right]_{\phi_{\mathrm{ST}}}^{\phi_{\mathrm{EX}}}
$$

Where $\theta$ is the tool angle engagement, $\phi_{\mathrm{EX}}$ and $\phi_{\mathrm{ST}}$ the exit and start angles. $\operatorname{Re}\left[G_{\mathrm{y}}\left(i \omega_{\mathrm{c}}\right)\right]$ is the real part of the structural transfer function of a system with one degree of freedom:

$$
\operatorname{Re}\left[G_{y}\left(i w_{\mathrm{c}}\right)\right]=\frac{1}{k} \frac{1-d^{2}}{\left(1-d^{2}\right)^{2}-4 \xi d^{2}}
$$


Where $d=\omega_{\mathrm{c}} / \omega_{0}, \omega_{0}$ the natural pulsation, $k$ the stiffness and $\xi$ the damping ratio. The link between the chatter frequency $\omega_{\mathrm{c}}$ and the spindle speed, is:

$$
N=\frac{60 \omega_{c}}{z\left[2 m \pi+2 \pi-2 \arctan \left[\left(d^{2}-1\right) / 2 \xi d\right]\right]}
$$

Equations (19) and (22) constitute a system of equations parameterised in $m$ and $\omega_{\mathrm{c}}$, it is then possible to plot the stability lobes for each mode of vibration of the wall. With this model it is possible to plot the 3D stability lobes of the finish milling of the wall (see Figure 8).

\section{Experimental work}

The cutting tests were carried out on a three-axis high speed milling machine, Kondia HS-1000, with a 24,000 rpm spindle. The tool used for the thin wall was an end mill with four flutes, a diameter of $12 \mathrm{~mm}, 45^{\circ}$ helix angle and a corner radius of $0.15 \mathrm{~mm}$. The cutting coefficients are $K_{\mathrm{t}}=700 \mathrm{MPa}$ and $k_{\mathrm{r}}=0.3$. For the floor, a bull-nose end mill was selected with a diameter of $16 \mathrm{~mm}, 2$ flutes and a corner radius of $2.5 \mathrm{~mm}, 30^{\circ}$ helix angle. The cutting coefficients for the bull-nose part are $K_{\mathrm{t}}=1723.3-369.44 \times z \mathrm{MPa}$, $K_{\mathrm{r}}=558.35-198.93 \times z \mathrm{MPa}, K_{\mathrm{a}}=48.26+52.15 \times z \mathrm{MPa}$ and for the frontal part $K_{\mathrm{t}}=804.73 \mathrm{MPa}, K_{\mathrm{r}}=65.49 \mathrm{MPa}$ and $K_{\mathrm{a}}=174.02 \mathrm{MPa}$. Figure 6 shows the experimental set-up, where the fixtures allow free vibration of the walls and the floor.

Figure 6 Machining set-up (see online version for colours)

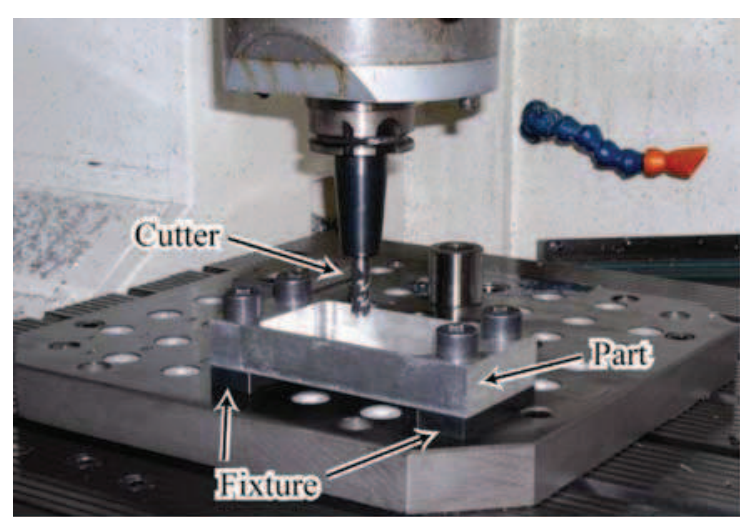

\subsection{Experimental procedure for the floor}

The floor was machined in five steps as it is explained in Section 3 with a feedrate of $0.05 \mathrm{~mm} /$ tooth. Two tests were carried out. Test A, at the maximum spindle speed, 24,000 rpm and Test B, selecting, for each step, an optimal spindle speed using the stability lobes. The lobes calculated did not allow machining the whole part with a single spindle speed. So, for Test B, the spindle speed was 24,000, 21,550, 21,300, 19,650 and 20,000 rpm for Steps 1-5, respectively (see Figure 7). 
Figure 7 3D stability lobes for the floor testing (see online version for colours)

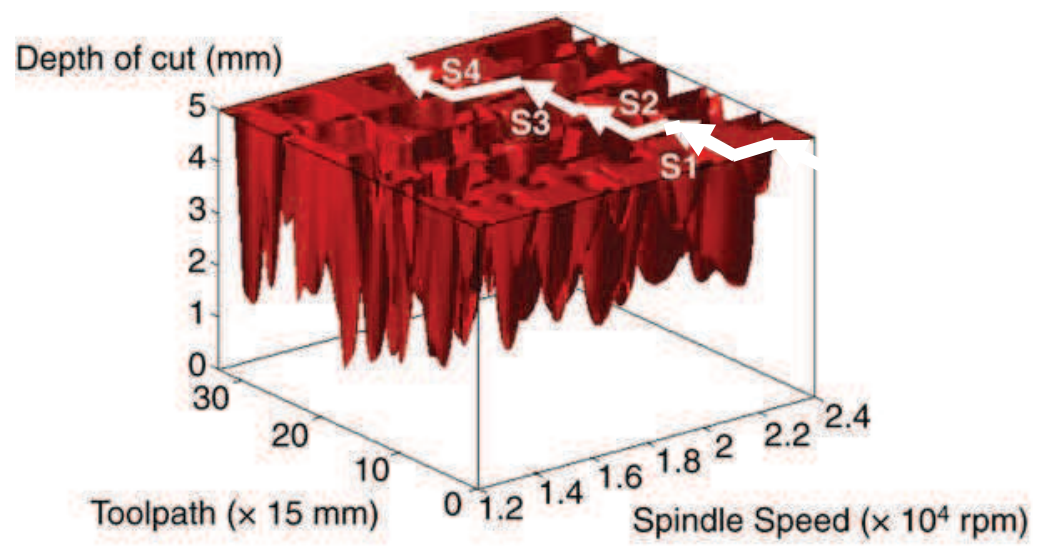

\subsection{Experimental procedure for the wall}

The wall was down-milled in finishing with a radial immersion of $0.1 \mathrm{~mm}$, and a feedrate of $0.05 \mathrm{~mm} /$ tooth. The axial depth of cut was chosen with the stability level in the centre of the wall machining where the available depth of cut is smaller (see Figure 8). Another test was also performed with a depth of cut of $3 \mathrm{~mm}$. The spindle speed is chosen with the stability lobes. In this case, it is the maximum: $24,000 \mathrm{rpm}$.

Figure 8 3D stability lobes for the wall (see online version for colours)

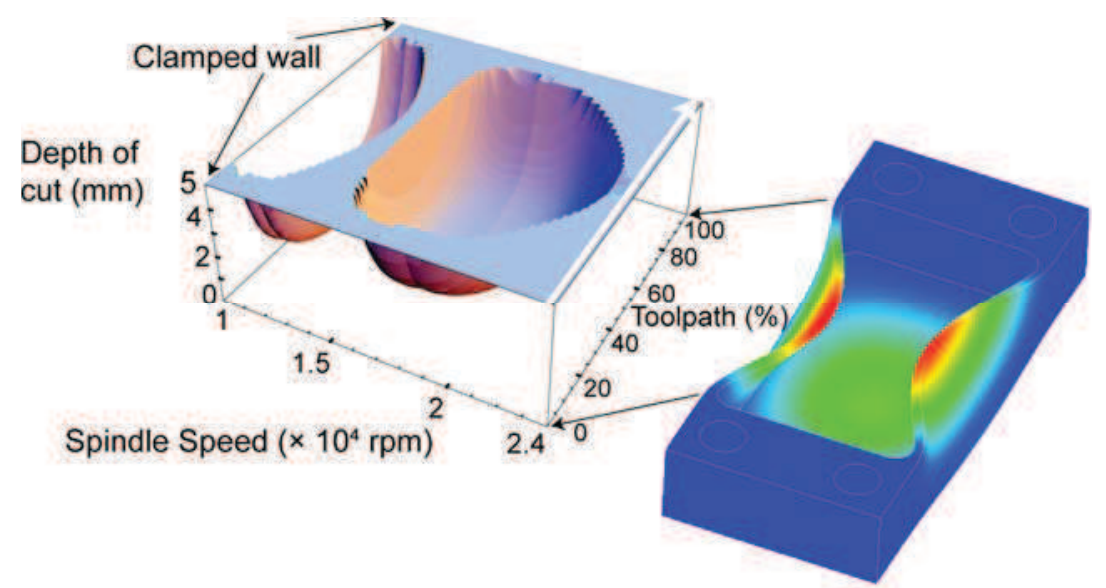

\subsection{Results}

The study of the floors has been approached focusing on each area of each of the five steps, instead of considering every step as a whole. The measurements are summarised in Figures 9 and 10, surface location error and surface roughness in $R_{\mathrm{a}}$, where cells with grey background mean out of tolerances in Section 2. 
Figure 9 Surface location error in $\mu \mathrm{m}$ of each area of the part. Left: Test A. Right: Test B (see online version for colours)

\begin{tabular}{|c|c|c|c|c|c|}
\hline & $\mathrm{s} 4$ & $\mathrm{~s} 2$ & $\mathrm{s1}$ & $\mathrm{s} 3$ & $\mathrm{s5}$ \\
\hline $\mathrm{a} 1$ & 5 & 5 & 11 & 0 & -5 \\
\hline $\mathrm{a} 2$ & -9 & 2 & 2 & -4 & -12 \\
\hline $\mathrm{a} 3$ & -22 & -3 & -9 & -17 & -20 \\
\hline $\mathrm{a} 4$ & -18 & -1 & 3 & -16 & -24 \\
\hline $\mathrm{a} 5$ & -11 & 12 & 16 & -15 & -24 \\
\hline $\mathrm{a} 6$ & $\mathrm{I}$ & 13 & 18 & -14 & -3 \\
\hline
\end{tabular}

\begin{tabular}{|c|c|c|c|c|c|}
\hline & $s 4$ & $s 2$ & $s 1$ & $s 3$ & $s 5$ \\
\hline a1 & 5 & 1 & 15 & -7 & -9 \\
\hline a2 & -11 & -9 & 24 & -24 & -15 \\
\hline $\mathrm{a} 3$ & -22 & -10 & 31 & -36 & -26 \\
\hline $\mathrm{a} 4$ & -21 & -4 & 25 & -50 & -27 \\
\hline $\mathrm{a} 5$ & -15 & 0 & 21 & -28 & -27 \\
\hline $\mathrm{a} 6$ & -1 & 0 & 20 & -18 & -9 \\
\hline
\end{tabular}
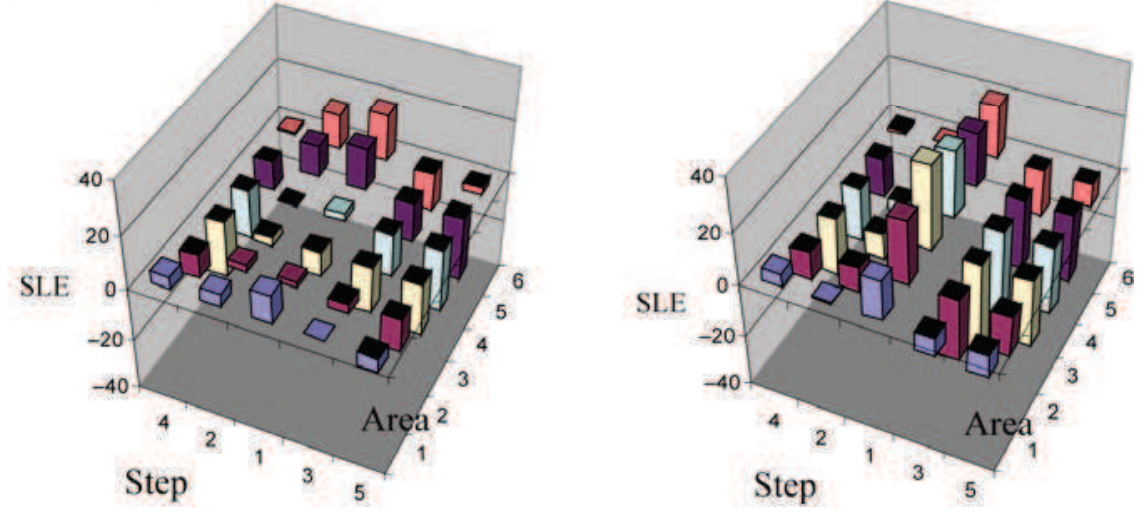

Figure 10 Surface roughness $R_{\mathrm{a}}$ in $\mu \mathrm{m}$ of each area of the part. Left: Test A. Right: Test B (see online version for colours)

\begin{tabular}{|c|c|c|c|c|c|}
\hline & $\mathrm{s} 4$ & $\mathrm{~s} 2$ & $\mathrm{~s} 1$ & $\mathrm{~s} 3$ & $\mathrm{s5}$ \\
\hline $\mathrm{al}$ & 0.46 & 0.83 & 1.13 & 0.83 & 0.69 \\
\hline $\mathrm{a} 2$ & 2.04 & 1.15 & 2.29 & 0.38 & 0.89 \\
\hline $\mathrm{a} 3$ & 2.67 & 1.50 & 3.86 & 0.67 & 2.02 \\
\hline $\mathrm{a} 4$ & 3.12 & 2.36 & 1.92 & 1.77 & 3.17 \\
\hline $\mathrm{a} 5$ & 1.55 & 1.19 & 0.70 & 1.57 & 1.32 \\
\hline $\mathrm{a} 6$ & 1.28 & 1.01 & 0.73 & 1.24 & 1.14 \\
\hline
\end{tabular}

\begin{tabular}{|c|c|c|c|c|c|}
\hline & $s 4$ & $s 2$ & $s 1$ & $s 3$ & $s 5$ \\
\hline a1 & 1.62 & 2.80 & 0.73 & 0.86 & 1.18 \\
\hline a2 & 2.69 & 0.91 & 0.93 & 2.04 & 1.27 \\
\hline a3 & 3.12 & 1.04 & 0.72 & 1.17 & 0.67 \\
\hline a4 & 2.81 & 1.05 & 0.91 & 1.62 & 0.32 \\
\hline a5 & 1.58 & 0.71 & 0.52 & 1.30 & 0.65 \\
\hline a6 & 0.93 & 0.93 & 0.30 & 1.56 & 1.43 \\
\hline
\end{tabular}
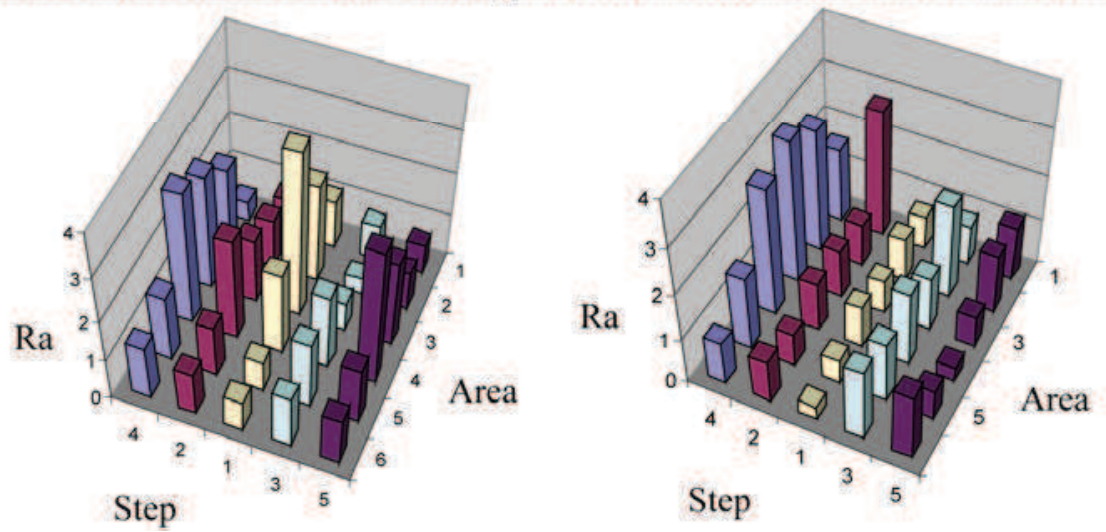

The surface location error is measured as the relative height of each area in microns related to the surface created with the four corners of the part. 
Table 1 gives the predicted and measured stability in each floor, where 's' means stable, ' $u$ ' unstable and ' $u / \mathrm{s}$ ' means that the cutting conditions selected are $0.5 \mathrm{~mm}$ above/below the limit of stability. The stability was determined analysing the FFT of the recorded noise during the machining.

Table 1 Predicted $(p)$ and measured $(m)$ stability for each area

\begin{tabular}{|c|c|c|c|c|c|c|c|c|}
\hline & \multicolumn{2}{|c|}{$S 4(\downarrow)$} & \multicolumn{2}{|c|}{$S 2(\downarrow)$} & \multicolumn{2}{|c|}{$S 3(\uparrow)$} & \multicolumn{2}{|c|}{$S 5(\uparrow)$} \\
\hline & $p$ & $m$ & $p$ & $m$ & $p$ & $m$ & $p$ & $m$ \\
\hline \multicolumn{9}{|c|}{ Test A } \\
\hline 1 & $\mathrm{~S}$ & $\mathrm{~s}$ & S & $\mathrm{s}$ & $\mathrm{S}$ & $\mathrm{s}$ & $\mathrm{S}$ & $\mathrm{S}$ \\
\hline 2 & $\mathrm{u} / \mathrm{s}$ & $\mathrm{u}$ & $\mathrm{u}$ & S & $\mathrm{u}$ & $\mathrm{u}$ & s & $\mathrm{u}$ \\
\hline 3 & $\mathrm{u}$ & $\mathrm{u}$ & $\mathrm{u}$ & $\mathrm{u}$ & $\mathrm{u}$ & $\mathrm{u}$ & s & $\mathrm{u}$ \\
\hline 4 & $\mathrm{u}$ & $\mathrm{u}$ & $\mathrm{u}$ & $\mathrm{u}$ & $\mathrm{u}$ & $\mathrm{u}$ & $\mathrm{u}$ & $\mathrm{u}$ \\
\hline 5 & S & $\mathrm{u}$ & $\mathrm{u}$ & $\mathrm{u}$ & $\mathrm{u}$ & $\mathrm{u}$ & $\mathrm{u}$ & $\mathrm{u}$ \\
\hline 6 & s & $\mathrm{u}$ & s & $\mathrm{u}$ & $\mathrm{S}$ & s & $\mathrm{s}$ & $\mathrm{u}$ \\
\hline \multicolumn{9}{|c|}{ Test B } \\
\hline 1 & $\mathrm{~s}$ & $\mathrm{~s}$ & $\mathrm{~s}$ & $\mathrm{~s}$ & $\mathrm{~S}$ & s & $\mathrm{s}$ & $\mathrm{s}$ \\
\hline 2 & $\mathrm{u} / \mathrm{s}$ & $\mathrm{s}$ & s & s & $\mathrm{S}$ & $\mathrm{u}$ & $\mathrm{s}$ & $\mathrm{u}$ \\
\hline 3 & $\mathrm{u} / \mathrm{s}$ & $\mathrm{u}$ & $\mathrm{u} / \mathrm{s}$ & $\mathrm{s}$ & $\mathrm{u} / \mathrm{s}$ & $\mathrm{u}$ & S & $\mathrm{s}$ \\
\hline 4 & $\mathrm{u} / \mathrm{s}$ & $\mathrm{u}$ & $\mathrm{u} / \mathrm{s}$ & $\mathrm{u}$ & $\mathrm{u} / \mathrm{s}$ & $\mathrm{u}$ & $\mathrm{s}$ & $\mathrm{s}$ \\
\hline 5 & $\mathrm{~s}$ & $\mathrm{u}$ & S & $\mathrm{S}$ & $\mathrm{u} / \mathrm{s}$ & S & S & $\mathrm{S}$ \\
\hline 6 & $\mathrm{~S}$ & $\mathrm{~s}$ & $\mathrm{~s}$ & $\mathrm{~s}$ & $\mathrm{~s}$ & S & S & $\mathrm{s}$ \\
\hline
\end{tabular}

Only in $77 \%$ of the cases the predicted matches the measured, though the reason can be found in the errors of the models, the stability model and the FEM model but also in the changing modal parameters and tool position, which result in a delay in the chatter appearance. These transitory effects are not taking into account the linear stability model and can explain discrepancies between the experiment and the modelling. This means that cases predicted as unstable are stable, for example, rows 4-1 in Step 3 of Test B. Also, once chatter appears, when stable conditions are reached again, it takes some time to recover the stability. This results in cases with predicted stability that are unstable, for example, rows 2-3 in Step 2 of Test A.

Figure 11 Thin wall machined with a depth of cut of $5 \mathrm{~mm}$ (see online version for colours)

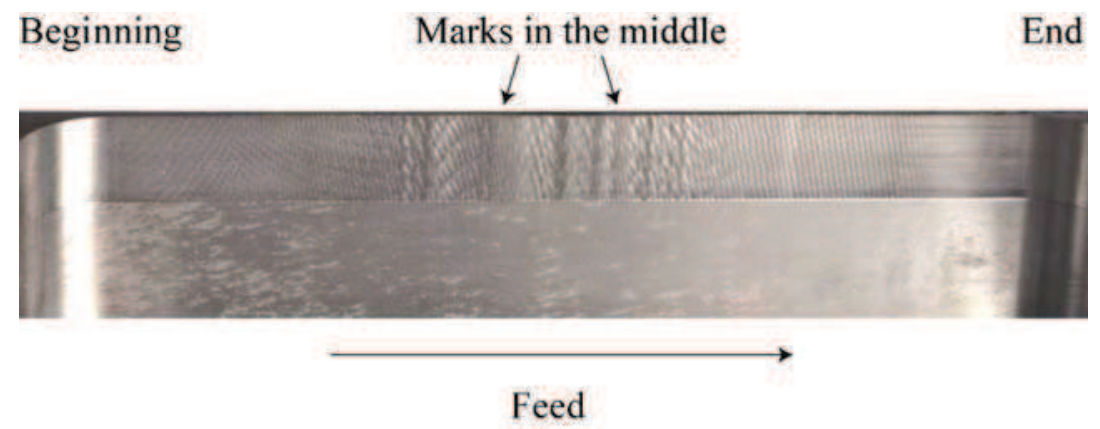


Regarding the walls, Figure 11 shows the machined thin wall with the cutting conditions mentioned above. The machining was unstable for a depth of cut of $5 \mathrm{~mm}$, in fact, the marks appear only in the middle of the wall, where the apparent stiffness is lower (see Figure 11). On the other hand, the test with a depth of cut of $3 \mathrm{~mm}$ was stable, with a good surface roughness without any marks. It can be concluded that the real limiting depth of cut was lower than the one calculated with the lobes.

\subsection{Comparison}

Regarding the surface location error, in both tests, the tool tends to overcut especially in the most flexible areas, rows 3 and 4 in Figure 9. In general, the overcut is higher in the Test B, and it could be explained by the higher forced vibration when machining near a modal frequency. On the other hand, it cannot be mentioned that stability always leads to a higher overcut.

Comparing the surface finish, there is very little difference between Tests A and B (see Figure 12). Again, it is very difficult to relate the surface finish to the stability of the milling, not always the finish is better in the stable areas. There is only one case out of tolerances, in Test $\mathrm{A}$, but even narrowing the requirements in $R_{\mathrm{a}}$, there would be both stable and unstable cases out of tolerances.

The machining of the wall is less difficult, because it has less modes of vibration and little material removal (see Figure 8). The 3D lobes make possible to understand better the phenomena: near the clamping, the depth of cut increases. There remains inaccuracies in the modelling, in particular with accuracy of the linear cutting law at low radial immersion (Lapoujoulade et al., 2002).

Figure 12 Left: Test B, right: Test A (see online version for colours)
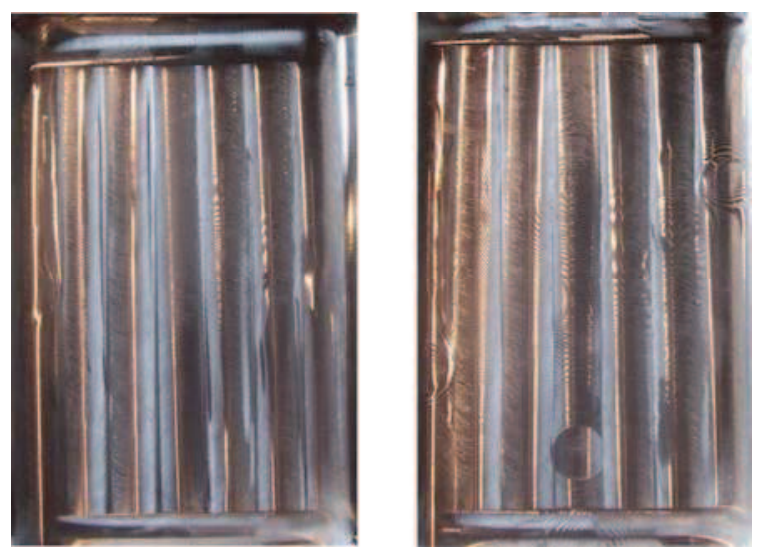

\section{Conclusions}

The prediction of stability in real parts is a very complex problem. Depending on the geometry, different models have to be used, for thin walls and thin floors. The removal of material implies that the modal parameters are continuously changing, as well as the tool position over the part. In addition, depending on the part, at high speed cutting conditions several high frequency modes can be involved in the calculus. 
The 3D stability lobes plot the traditional stability lobes along the toolpath, so the most productive stable conditions can be chosen. However, depending on the complexity of the part and the change in the modal parameters, several spindle speeds or at least a continuously changing spindle speed must be selected. This approach can be very problematic in an industrial context because not all the spindles allow such variations, so it may only be effective with simpler geometries and the time calculus is more important with a simple model. A good test of these techniques has been made in this paper.

In prospects, we are working on the improvement of the model to limit the assumptions. Also, it will be interesting to show other optimisation solutions like, the variable pitch tool, the spindle speed variation, etc.

\section{Acknowledgements}

The authors acknowledge the co-financial support of the European Union by means of the Interreg IIIa Action AEROSFIN (The Pyrenees Manufacturing Aeronautical Spanish-French Interregional Network). Thanks are also addressed to Mr. Jovanny Pacheco for his valuable help.

\section{References}

Altintas, Y. (2001) 'Analytical prediction of three dimensional chatter stability in milling', The Japan Society of Mechanical Engineers, International Journal Series, Vol. 44, pp.717-723.

Bayly, P.V., Halley, J.E., Mann, B.P. and Davies, M.A. (2003) 'Stability of interrupted cutting by temporal finite element analysis', Journal of Manufacturing Science and Engineering, Vol. 125, pp.220-225.

Bravo, U., Altuzarra, O., López de Lacalle, L.N., Sánchez, J.A. and Campa, F.J. (2005) 'Stability limits of milling considering the flexibility of the workpiece and the machine', International Journal of Machine Tools and Manufacture, Vol. 45, pp.1669-1680.

Budak, E. (1994) 'Mechanics and dynamics of milling thin walled structures', PhD Thesis, University of British Columbia.

Budak, E. and Altintas, Y. (1998a) 'Analytical prediction of the chatter stability in milling Part I: general formulation', Journal of Dynamic Systems, Measurement and Control, Vol. 120, pp.22-30.

Budak, E. and Altintas, Y. (1998b) 'Analytical prediction of the chatter stability in milling Part II: application of the general formulation to common milling systems', Journal of Dynamic Systems, Measurement and Control, Vol. 120, pp.31-36.

Campa, F.J., López de Lacalle, L.N., Lamikiz, A. and Sánchez, J.A. (2007) 'Selection of cutting conditions for a stable milling of flexible parts with bull-nose end milling tools', Journal of Materials Processing Technology, Vol. 191, pp.279-282.

Davies, M.A. and Balachandran, B. (2000) 'Impact dynamics in milling of thin walled structures', Nonlinear Dynamics, Vol. 22, pp.375-392.

Gradisek, J., Kalveram, M., Insperger, T., Weinert, K., Stépán, G., Govekar, E. and Grabec, I. (2005) 'On stability prediction for milling', International Journal of Machine Tool and Manufacture, Vol. 45, pp.769-781.

Jensen, S.A. and Shin, Y.C. (1999) 'Stability analysis in face milling operation, Part - I: theory of stability lobe prediction', Journal of Manufacturing Science and Engineering, Vol. 121, pp.600-605. 
Lapujoulade, F., Mabrouki, T. and Raïssi, K. (2002) 'Prédiction du comportement vibratoire du fraisage latéral de finition des pièces à parois minces', Mécanique et Industrie, Vol. 3, pp.403-418.

Smith, S. and Dvorak, D. (1998) 'Tool path strategies for high speed milling aluminium workpieces with thin webs', Mechatronics, Vol. 8, pp.291-300.

Thevenot, V., Arnaud, L., Dessein, G. and Cazenave-Larroche, G. (2006a) 'Influence of material removal on the dynamic behaviour of thin walled structure in peripheral milling', Machining Science and Technology, Vol. 10, pp.275-287.

Thevenot, V., Arnaud, L., Dessein, G. and Cazenave-Larroche, G. (2006b) 'Integration of dynamic behaviour in stability lobes method: 3D lobes construction and application to thin walled structure milling', International Journal of Advanced Manufacturing Technology, Vol. 27, pp.638-644.

Tlusty, J. and Polacek, M. (1963) 'The stability of machine tool against self exited vibrations in machining', Proceedings of the International Research in Production Engineering Conference, ASME Press, Pittsburgh, pp.465-474.

Tobias, S.A. and Fishwick, W. (1958) 'A theory of regenerative chatter', The Engineer, London. 